\title{
Effect of pre-freezing and saccharide types in freeze-drying of siRNA lipoplexes on gene-silencing effects in the cells by reverse transfection
}

\author{
MIN TANG, SUBIN HU and YOSHIYUKI HATTORI \\ Department of Molecular Pharmaceutics, Hoshi University, Shinagawa, Tokyo 142-8501, Japan
}

Received April 8, 2020; Accepted July 2, 2020

DOI: $10.3892 / \mathrm{mmr} .2020 .11419$

\begin{abstract}
Our previous study reported that reverse (Rev)-transfection with small interfering RNA (siRNA)/cationic liposome complexes (siRNA lipoplexes) freeze-dried in trehalose or sucrose solution resulted in high gene-silencing activity in cells. The current study investigated whether pre-freezing or saccharide types present during the freeze-drying of siRNA lipoplexes affected gene-silencing in cells after Rev-transfection. Three types of cationic cholesterol derivatives and three types of dialkyl or trialkyl cationic lipids were used for the preparation of cationic liposomes. Additionally, six types of siRNA lipoplexes were vacuum-dried in trehalose or sucrose solution without a pre-freezing process in multi-well plates. A strong gene-silencing activity after Rev-transfection was observed regardless of the cationic lipid types in the cationic liposomes. It was also investigated whether saccharide types in the freeze-drying of siRNA lipoplexes affected gene-silencing after Rev-transfection. siRNA lipoplexes freeze-dried in monosaccharides (glucose, fructose, galactose or mannose), disaccharides (maltose, lactose, lactulose or cellobiose) and trisaccharide solution (raffinose or melezitose) demonstrated high gene-silencing activity. However, following Rev-transfection with siRNA lipoplexes freeze-dried in monosaccharides or trisaccharides, certain saccharides induced cytotoxicity and/or off-target effects. The results of the current study indicated that disaccharides may be suitable for the preparation of vacuum-dried or freeze-dried siRNA lipoplexes for Rev-transfection.
\end{abstract}

\section{Introduction}

Small interfering RNAs (siRNAs) are the widely used for the suppression of targeted gene expression in cells (1). For

Correspondence to: Professor Yoshiyuki Hattori, Department of Molecular Pharmaceutics, Hoshi University, 2-4-41 Ebara, Shinagawa, Tokyo 142-8501, Japan

E-mail: yhattori@hoshi.ac.jp

Key words: cationic liposome, small interfering RNA, reverse transfection, monosaccharide, disaccharide, trisaccharide, vacuum-dry, freeze-dry the analysis of gene function with siRNA, reproducible transfections with a large set of siRNAs in a multi-well plate is required (2). For effective transfection of siRNAs into cells, cationic liposomes are currently the most widely used carrier (3). However, siRNA and cationic liposome complexes (siRNA lipoplexes) are unstable when stored in solution at room temperature, but they can be stabilized by drying. Therefore, for transfection of a large set of siRNAs, reverse (Rev) transfection with freeze-dried siRNA lipoplexes are the validated means. In Rev-transfection with freeze-dried siRNA lipoplexes, the siRNA lipoplex solution is added into the well of cell culture plates, followed by freeze-drying, and at the time of transfection, a cell suspension is added to the culture plate well. Rev-transfection can reduce the time for transfection if a large set of siRNA lipoplexes are freeze-dried in advance in multi-well plates.

A typical freeze-drying process consists of three main phases: Freezing and primary and secondary drying (4). The size of siRNA lipoplexes usually increases after freeze-drying because of the influence of severe stress during the freezing, lyophilizing, and rehydration processes, which can damage the siRNA lipoplexes (5). Therefore, disaccharides such as sucrose and trehalose have been used as cryoprotectants for the stabilization of siRNA lipoplexes during the freeze-drying and rehydration processes (6-9). During freeze-drying, water molecules associated with the polar head groups of hydrated phospholipids of the liposomal membrane are replaced by disaccharide molecules, which protect liposomes from aggregation and fusion between siRNA lipoplexes. Regarding the Rev-transfection of siRNA or micro (mi)RNA, chitosan and TransIT-TKO ${ }^{\circledR}$ transfection reagent (cationic polymer/lipid formulation) exhibited effective gene-silencing in H1299 and RAW264.3 cell lines when their complexes with siRNA were freeze-dried in the presence of $10 \%$ (292 mM) sucrose in a 24-well plate (7). Furthermore, Rev-transfection with commercially available Lipofectamine 2000 lipoplexes introduced siRNA at high efficiency into various types of cell lines when they were vacuum-dried in the presence of dextran and polyvinyl alcohol (PVA) in a 24-well plate (10). In addition, Rev-transfection with Lipofectamine 2000 lipoplexes freeze-dried in Opti-MEM on a tissue culture plate showed high transfection efficiency of miRNA in mesenchymal stem cells (11). Previously, we reported that the presence of trehalose or sucrose in the freeze-drying of siRNA lipoplexes increased 
the long-term stability of siRNA lipoplexes without apparent loss of gene-silencing activity by Rev-transfection (12). However, to the best of our knowledge, there are still few reports on the application of Rev-transfection with freeze-dried siRNA lipoplexes in multi-well plates for the transfection of siRNAs into cells.

In this study, we examined the effect of freezing and saccharide types in the freeze-drying of siRNA lipoplexes on the efficiency of gene-silencing in cells using Rev-transfection. Here, we found that vacuum-drying of siRNA lipoplexes in trehalose or sucrose solution without a pre-freezing process also resulted in high gene-silencing activity upon Rev-transfection. In addition, the presence of disaccharides such as maltose, lactose, lactulose, and cellobiose during the freeze-drying of siRNA lipoplexes exhibited gene-silencing activity without cytotoxicity by Rev-transfection, compared with those of monosaccharides or trisaccharides. This study provides valuable information about the Rev-transfection with freeze-dried or vacuum-dried siRNA lipoplexes for efficient siRNA delivery into the cells with a large set of siRNAs in a multi-well plate.

\section{Materials and methods}

Materials.Cholesteryl(3-((2-hydroxyethyl)amino)propyl)carbamate hydroiodide (HAPC-Chol) was synthesized as described previously (13). $\mathrm{N}$-(2-(2-Hydroxyethylamino)ethyl)cholesteryl3-carboxamide (OH-Chol) and cholesteryl (2-((2-hydroxyethyl) amino)ethyl)carbamate (OH-C-Chol) were synthesized as described previously (14). 1,2-Dioleoyl-3-trimethylammonium-propane methyl sulfate salt (DOTAP) was obtained from Avanti Polar Lipids Inc. Dimethyldioctadecylammonium bromide (DDAB, product name: DC-1-18) and 11-((1,3bis(dodecanoyloxy)-2-((dodecanoyloxy)methyl)propan-2-yl) amino)- $N, N, N$-trimethyl-11-oxoundecan-1-aminium bromide (product name: TC-1-12) were obtained from Sogo Pharmaceutical Co., Ltd.. 1,2-Dioleoyl-sn-glycero-3-phosphoethanolamine (DOPE, COATSOME ME-8181) was obtained from NOF Co., Ltd.. Glucose, fructose, galactose, mannose, sucrose, trehalose dihydrate, maltose monohydrate, lactose monohydrate, lactulose, cellobiose, and raffinose pentahydrate were obtained from Wako Pure Chemical Industries, Ltd.. Melezitose was purchased form Sigma-Aldrich Co. LLC. All other chemicals were of the highest grade available.

Small interfering RNAs. siRNAs targeting nucleotides of firefly luciferase (Luc siRNA), and non-silencing siRNA [control (Cont) siRNA] as a negative control for Luc siRNA were synthesized by Sigma Genosys. The siRNA sequences of the Luc siRNA were: Sense strand: 5'-CCGUGGUGUUCG UGUCUAAGA-3', and antisense strand: 5'-UUAGACACG AACACCACGGUA-3 (15). The siRNA sequences of the Cont siRNA were: Sense strand: 5'-GUACCGCACGUCAUUCGU AUC-3', and antisense strand: 5'-UACGAAUGACGUGCG GUACGU-3' (14).

Preparation of cationic liposomes and siRNA lipoplexes. Cationic cholesterol derivative-based liposomes were prepared from OH-Chol/DOPE (composition designated as LP-OH), $\mathrm{OH}-\mathrm{C}-\mathrm{Chol} / \mathrm{DOPE}$ (composition designated as LP-OH-C), and HAPC-Chol/DOPE (composition designated as LP-HAPC) at a molar ratio of 3:2 (16). The cationic liposomes including dialkyl or trialkyl cationic lipids were prepared from DOTAP/DOPE (composition designated as LP-DOTAP), DDAB/DOPE (composition designated as LP-DDAB), and TC-1-12/DOPE (composition designated as LP-TC-1-12) at a molar ratio of 1:1 (16).

For the preparation of cationic liposomes using a thin-film hydration method, cationic lipid and DOPE were dissolved in chloroform, and the chloroform was evaporated under vacuum on a rotary evaporator at $60^{\circ} \mathrm{C}$ to obtain a thin film. The thin film was hydrated with water at $60^{\circ} \mathrm{C}$ by vortex mixing. The hydrated liposomes were placed in an eggplant flask and sonicated using a bath-type sonicator (Bransonic ${ }^{\circledR} 2510 \mathrm{~J}-\mathrm{MTH}$, $42 \mathrm{kHz}, 100 \mathrm{~W}$, Branson UL Trasonics Co.) for 5-10 min at room temperature.

To prepare cationic liposome/siRNA complexes (siRNA lipoplexes), each liposome preparation was added to $50 \mathrm{pmol}$ siRNA at a charge ratio (+:-) of 7:1 for cationic liposomes composed of cationic cholesterol derivatives and DOPE $(14,16)$ or 4:1 for cationic liposomes composed of dialkyl or trialkyl cationic lipids and DOPE $(16,17)$ with vortex-mixing for $10 \mathrm{sec}$ and left at room temperature for $15 \mathrm{~min}$. The charge ratio (+:-) of liposomes:siRNA is expressed as the molar ratio of cationic lipid to siRNA phosphate.

Appearance of cakes after freeze-drying or vacuum-drying of saccharide solution. For comparison of appearance of cakes (dry powder) after freeze-drying and vacuum-drying of saccharide solution in 12-well plates, $125 \mu 1$ of 10, 25, 50, 100, or $150 \mathrm{mM}(0.34,0.86,1.71,3.42$ or $5.13 \%(\mathrm{w} / \mathrm{v})$, respectively) trehalose or sucrose solutions were sterilized using a $0.45 \mu \mathrm{m}$ filter, and then transferred into a 12 -well plate. In preparation for the freeze-dried saccharides, the plate was frozen at $-80^{\circ} \mathrm{C}$, and then dried in a high vacuum (10-20 Pa) using a freeze-dryer [(FDU-540, Tokyo Rikakikai Co. (EYELA)], equipped with dry chamber (DRC-2L, EYELA). In the preparation of vacuum-dried saccharides, the plate was dried in a high vacuum (10-20 Pa) without pre-freezing.

For comparison of cake volume between freeze-dried saccharides in $5 \mathrm{ml}$ vial, $5 \mathrm{ml}$ of 25 and $100 \mathrm{mM}$ glucose, fructose, galactose, mannose, sucrose, trehalose, maltose, lactose, lactulose, cellobiose, raffinose, or melezitose solution were transferred into $5 \mathrm{ml}$ vial. The vials were frozen at $-80^{\circ} \mathrm{C}$ and then dried in a high vacuum (10-20 Pa).

Size and $\zeta$-potential of reconstituted siRNA lipoplexes. For measurement of the size and $\zeta$-potential of siRNA lipoplexes, siRNA lipoplexes were formed by the addition of cationic liposomes to $5 \mu \mathrm{g}$ Cont siRNA with vortex-mixing for 10 sec and left at room temperature for $15 \mathrm{~min}$. In the preparation of vacuum-dried siRNA lipoplexes, each lipoplex was diluted in $933 \mu \mathrm{l}$ of 10,50 or $100 \mathrm{mM}$ trehalose or sucrose solution sterilized using a $0.45 \mu \mathrm{m}$ filter [125 $\mu \mathrm{l}$ saccharide solution per $50 \mathrm{pmol}(0.67 \mu \mathrm{g})$ siRNA], and then transferred to a 6-well plate. The plates were dried in a high vacuum. In the preparation of freeze-dried siRNA lipoplexes, each lipoplex with $5 \mu \mathrm{g}$ Cont siRNA was diluted in $933 \mu \mathrm{l}$ of 25 or $100 \mathrm{mM}$ mono-, di-, or trisaccharide solution sterilized using a $0.45 \mu \mathrm{m}$ filter, and then transferred to a 6 -well plate, followed 
by freezing at $-80^{\circ} \mathrm{C}$. The frozen plates were dried in a high vacuum.

Vacuum-dried and freeze-dried siRNA lipoplexes were reconstituted with an appropriate volume $(\sim 1 \mathrm{ml})$ with water, and the particle size distributions (cumulant average particle size) of siRNA lipoplexes were measured by the cumulant method using a light-scattering photometer (ELS-Z2, Otsuka Electronics Co., Ltd.) at $25^{\circ} \mathrm{C}$. The $\zeta$-potentials were measured using an electrophoresis light-scattering method with ELS-Z2 at $25^{\circ} \mathrm{C}$.

Cell culture. Human breast cancer MCF-7 cells stably expressing firefly luciferase (MCF-7-Luc) which constructed by transfection of plasmid pcDNA3 containing the firefly luciferase (hLuc) gene from plasmid psiCHECK2 (Promega Corp.) were donated by Dr Kenji Yamato (University of Tsukuba, Tsukuba, Japan). MCF-7-Luc cells were grown in RPMI-1640 medium, supplemented with $10 \%$ heat-inactivated fetal bovine serum (FBS) and $1.2 \mathrm{mg} / \mathrm{ml} \mathrm{G} 418$ at $37^{\circ} \mathrm{C}$ in a $5 \% \mathrm{CO}_{2}$ humidified atmosphere.

Effect of pre-freezing of siRNA lipoplexes before vacuum-drying on gene-silencing by Rev-transfection. For the preparation for Rev-transfection with vacuum-dried siRNA lipoplexes, siRNA lipoplexes were formed by the addition of cationic liposomes to 50 pmol $(0.67 \mu \mathrm{g})$ Cont siRNA or Luc siRNA by vortex-mixing for $10 \mathrm{sec}$ and left at room temperature for $15 \mathrm{~min}$. Each lipoplex was diluted in $125 \mu \mathrm{l}$ of $10,25,50,100,150$, or $280 \mathrm{mM}[0.34$, $0.86,1.71,3.42,5.13$, or $9.52 \%(\mathrm{w} / \mathrm{v})$, respectively] trehalose or sucrose solution sterilized using a $0.45 \mu \mathrm{m}$ filter, and then transferred into 12 -well plates (50 pmol siRNA/well). These plates were dried in a high vacuum and then stored at room temperature in a desiccator until use.

For Rev-transfection with vacuum-dried siRNA lipoplexes on 12-well plate, $1 \times 10^{5} \mathrm{MCF}$-7-Luc cells were suspended in $1 \mathrm{ml}$ of medium supplemented with $10 \% \mathrm{FBS}$, and then the suspension was added to the well (final $50 \mathrm{nM}$ siRNA concentration). The molarity of the medium after rehydration (final 1.25, 3.125, 6.25, 12.5, 18.75, or $35 \mathrm{mM}[0.04,011$, $0.21,0.43,0.64$, and $1.12 \%(\mathrm{w} / \mathrm{v})$, respectively] trehalose or sucrose in medium) was maintained at $286-320$ mOsm, which was approximately equivalent to the physiological molarity. Forty-eight hours after transfection, the cells were lysed by the addition of $125 \mu \mathrm{l}$ of cell lysis buffer (Pierce ${ }^{\mathrm{TM}}$ Luciferase cell lysis buffer, Thermo Fisher Scientific Inc.) after washing with PBS, and subjected to one cycle of freezing $\left(-80^{\circ} \mathrm{C}\right)$ and thawing at $37^{\circ} \mathrm{C}$, followed by centrifugation at $15,000 \mathrm{~g}$ for $10 \mathrm{sec}$. Aliquots of $10 \mu \mathrm{l}$ of the supernatants of cell lysates were mixed with $50 \mu \mathrm{l}$ of PicaGene MelioraStar-LT Luminescence Reagent (Toyo Ink Mfg. Co., Ltd.), and the luminescence was measured as counts per sec (cps) using a chemoluminometer (ARVO $\mathrm{X} 2$, Perkin Elmer). The protein concentration of the supernatants was determined using BCA reagent (Thermo Fisher Scientific Inc.), with bovine serum albumin as a standard, and the luciferase activity (cps/ $\mu \mathrm{g}$ protein) was calculated. Luciferase activity (\%) was calculated as relative to the luciferase activity (cps/ $\mu \mathrm{g}$ protein) of untransfected cells.

Effect of saccharide types in freeze-drying of siRNA lipoplexes on gene-silencing by Rev-transfection. For the preparation for
Rev-transfection with freeze-dried siRNA lipoplexes, siRNA lipoplexes were formed by the addition of cationic liposomes to 50 pmol Cont siRNA or Luc siRNA by vortex-mixing for $10 \mathrm{sec}$ and left at room temperature for $15 \mathrm{~min}$. Each lipoplex was diluted in $125 \mu \mathrm{l}$ of various concentrations of mono-, di-, or trisaccharide solution sterilized using a $0.45-\mu \mathrm{m}$ filter, and then transferred to a 12 -well plate (50 pmol siRNA/well), followed by freezing at $-80^{\circ} \mathrm{C}$. The frozen plates were dried in a high vacuum and then stored at room temperature in a desiccator until use.

For Rev-transfection with freeze-dried siRNA lipoplexes, $1 \times 10^{5} \mathrm{MCF}-7-L u c$ cells were suspended in $1 \mathrm{ml}$ of medium supplemented with $10 \% \mathrm{FBS}$, and then the suspension was added to the well (final $50 \mathrm{nM}$ siRNA concentration). Forty-eight hours after transfection, luciferase activity was measured as described above.

Cytotoxicity of Rev-transfection with freeze-dried siRNA lipoplexes. Each lipoplex with 5 pmol Cont siRNA was diluted in $12.5 \mu \mathrm{l}$ of various concentrations of mono-, di-, or trisaccharide solution, and then the mixture was transferred to the wells of 96 -well plates ( 5 pmol siRNA/well). After freezing at $-80^{\circ} \mathrm{C}$, the plates were dried under high vacuum. MCF-7-Luc cells $\left(1 \times 10^{4}\right)$ were suspended in $100 \mu \mathrm{l}$ of medium supplemented with $10 \%$ FBS and then the suspension was added to the well (final $50 \mathrm{nM}$ siRNA concentration). After a 24-h incubation period, cell numbers were determined using a Cell Counting Kit-8. Cell viability was expressed as relative to the absorbance at $450 \mathrm{~nm}$ of cells added into wells without freeze-dried lipoplexes.

Statistical analysis. Data are presented as the mean \pm standard deviation of triple determinations. The statistical significance of differences between mean values was determined by Student's t-test using GraphPad Prism 4.0 (GraphPad Software, Inc.). Multiple measurement comparisons were performed by analysis of variance followed by one-way analysis of variance on ranks with post hoc Tukey test using GraphPad Prism 4.0. Each experiment was repeated $\geq 3$ times. $\mathrm{P} \leq 0.05$ was considered to indicate a statistically significant difference

\section{Results and Discussion}

Characterization of vacuum-dried siRNA lipoplexes after reconstitution. Lyoprotectants such as sucrose and trehalose are often used to improve the stability of liposomes or lipoplexes in freeze-drying (18). Previously, we demonstrated that regardless of the cationic lipid types used in cationic liposomes, Rev-transfection with siRNA lipoplexes freeze-dried in trehalose or sucrose solution could induce efficient gene-silencing in the cells (12). The freeze-drying process of siRNA lipoplexes consisted of freezing and primary and secondary drying in a high vacuum, and the freezing process of siRNA lipoplexes solution was performed before vacuum-drying. In this study, first, to investigate whether the freezing process before vacuum-drying of siRNA lipoplexes affected gene-silencing in the cells after Rev-transfection, we prepared vacuum-dried siRNA lipoplexes without pre-freezing process. Here, for the preparation of cationic liposomes, we used $\mathrm{OH}-\mathrm{Chol}, \mathrm{OH}-\mathrm{C}-\mathrm{Chol}$, and 
DOTAP

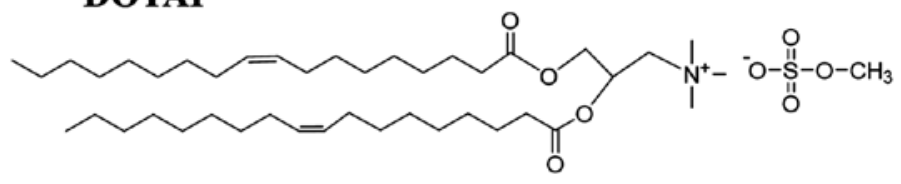

\section{TC-1-12}

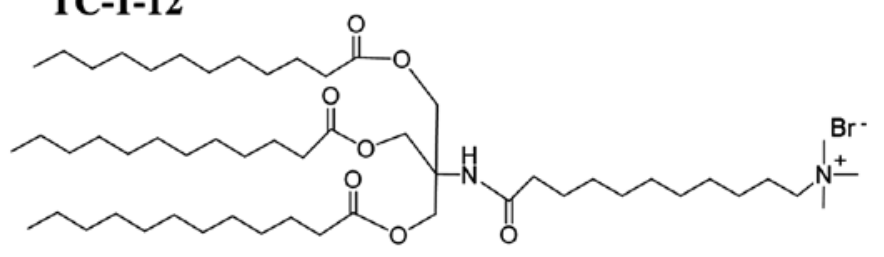

\section{DDAB}

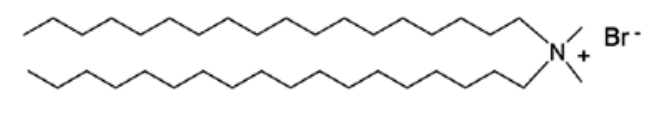

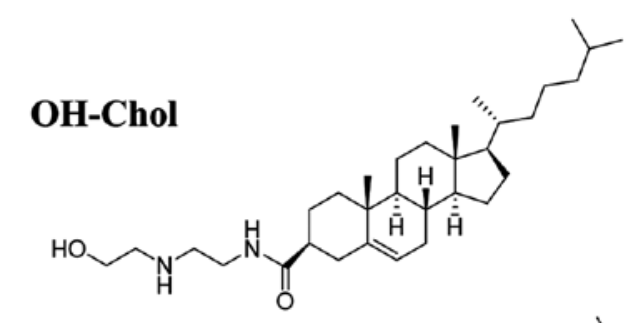
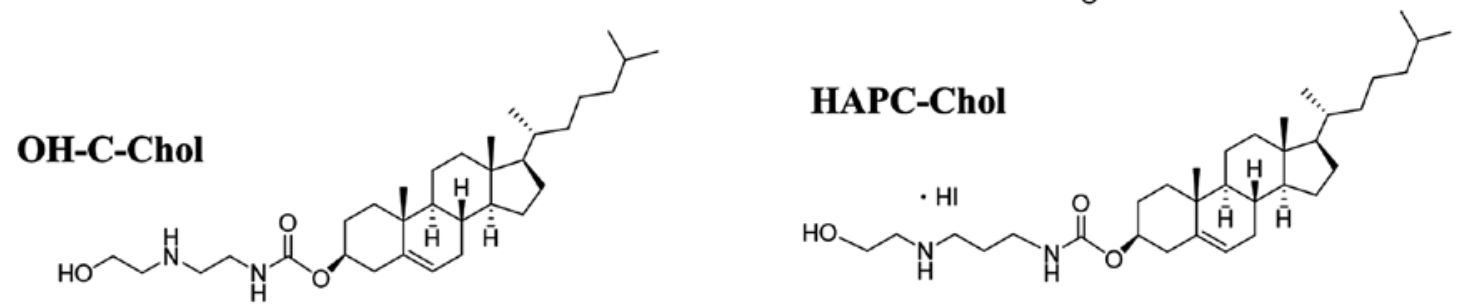

Figure 1. Structure of cationic cholesterol derivatives and cationic lipids with dialkyl or trialkyl chains. OH-Chol, $N$-(2-(2-hydroxyethylamino)ethyl) cholesteryl-3-carboxamide; OH-C-Chol, cholesteryl (2-((2-hydroxyethyl)amino)ethyl)carbamate; HAPC-Chol, cholesteryl (3-((2-hydroxyethyl)amino)propyl) carbamate hydroiodide; DOTAP, 1,2-dioleoyl-3-trimethylammonium-propane methyl sulfate salt; DDAB, dimethyldioctadecylammonium bromide; TC-1-12, 11-((1,3-bis(dodecanoyloxy)-2-((dodecanoyloxy)methyl)propan-2-yl)amino)- $N, N, N$-trimethyl-11-oxoundecan-1-aminium bromide.

HAPC-Chol as cationic cholesterol derivatives; DOTAP and DDAB as dialkyl cationic lipids; and TC-1-12 as a trialkyl cationic lipid (Fig. 1). For cationic liposomes with cationic cholesterol derivatives, LP-OH, LP-OH-C, and LP-HAPC were prepared from $\mathrm{OH}-\mathrm{Chol} / \mathrm{DOPE}, \mathrm{OH}-\mathrm{C}-\mathrm{Chol} / \mathrm{DOPE}$, and HAPC-Chol/DOPE, respectively, at a molar ratio of 3:2. In contrast, for cationic liposomes with dialkyl or trialkyl cationic lipids, LP-DOTAP, LP-DDAB, and LP-TC-1-12 were prepared from DOTAP/DOPE, DDAB/DOPE, and TC-1-12/DOPE, respectively, at a molar ratio of 1:1.

The sizes of the cationic liposomes prepared in this study were approximately $80-100 \mathrm{~nm}$ with a monodisperse distribution, and the $\zeta$-potentials were approximately $41-56 \mathrm{mV}$ (12). In the preparation of siRNA lipoplexes, we reported previously that the optimal charge ratios (+:-) were 7:1 for cationic liposomes composed of cationic cholesterol derivatives and 4:1 for cationic liposomes composed of dialkyl or trialkyl cationic lipids $(16,19)$; therefore, in subsequent experiments, we used siRNA lipoplexes formed at charge ratios (+:-) of 7:1 for LP-OH, LP-OH-C, and LP-HAPC and 4:1 for LP-DOTAP, LP-DDAB, and LP-TC-1-12, respectively. The sizes of siRNA lipoplexes were approximately $150-190 \mathrm{~nm}$, and the $\zeta$-potentials were approximately $34-47 \mathrm{mV}$ (12).

To examine whether vacuum-drying without pre-freezing affected the size of siRNA lipoplexes after rehydration, vacuum-dried siRNA lipoplexes were prepared in the presence of 10,50 , or $100 \mathrm{mM}$ trehalose or sucrose solution, and measured the sizes of the siRNA lipoplexes after rehydration with water (Table I). In vacuum-drying in $10 \mathrm{mM}$ disaccharide, siRNA lipoplexes exhibited a larger size (approximately 260-570 $\mathrm{nm}$ ), and in $50 \mathrm{mM}$ disaccharide, they were approximately 180-330 nm in size. However, siRNA lipoplexes were approximately $170-240 \mathrm{~nm}$ in size (0.19-0.26 in PDI) when they were vacuum-dried in $100 \mathrm{mM}$ trehalose or sucrose solution. These results indicated that the presence of $100 \mathrm{mM}$ disaccharide during vacuum-drying of siRNA lipoplexes did not greatly increase the size of siRNA lipoplexes regardless of the cationic lipid types in cationic liposomes.

Effect of freezing before vacuum-drying of siRNA lipoplexes on gene-silencing effect in the cells by Rev-transfection. To examine the effect of pre-freezing before vacuum-drying of siRNA lipoplexes on gene-silencing effect in the cells after Rev-transfection, each of the lipoplexes was diluted with solutions containing various concentrations of trehalose or sucrose, and then the mixtures were added into the wells of a 12-well plate, followed by vacuum-drying without pre-freezing (Fig. 2). In Rev-transfection with vacuum-dried siRNA lipoplexes in 12-well plates, we added $125 \mu \mathrm{l}$ of disaccharide solution per well for vacuum-drying of the siRNA lipoplexes. Because, in our previous study, siRNA lipoplexes freeze-dried with $125 \mu \mathrm{l}$ of $150 \mathrm{mM}$ disaccharide solution did not greatly induce the cytotoxic effect (12). The cakes after vacuum-drying of $125 \mu \mathrm{l}$ of $10,25,50,100,150$, and $280 \mathrm{mM}$ disaccharide solution contained $0.43,1.1,2.1,4.3,6.4$, and $12.0 \mathrm{mg}$ disaccharide per well, respectively. With increasing concentrations of trehalose or sucrose present during drying, larger cakes were observed on the wells after freeze-drying or vacuum-drying, and the large difference in appearance between the cakes after freeze-drying and vacuum-drying was not observed (Fig. S1).

After vacuum-drying of the siRNA lipoplexes, we reconstituted siRNA lipoplexes with MCF-7-Luc cells suspended in culture medium. As a result, LP-OH, LP-OH-C, LP-HAPC, LP-DOTAP, LP-DDAB, and LP-TC-1-12 lipoplexes with Luc siRNA did not suppress luciferase activity when their lipoplexes were vacuum-dried without disaccharides (Figs. 3 and 4). 
Table I. Particle size and $\zeta$-potential of small interfering RNA lipoplexes after rehydration of vacuum-dried lipoplexes.

A, $10 \mathrm{mM}$ trehalose

\begin{tabular}{lccc}
\hline Lipoplex $^{\mathrm{c}}$ & Size $^{\mathrm{b}}, \mathrm{nm}$ & PDI & $\zeta$-potential \\
& & & $\mathrm{mV}$ \\
\hline LP-OH & $483.9 \pm 22.0$ & $0.24 \pm 0.01$ & $39.4 \pm 1.1$ \\
LP-OH-C & $329.7 \pm 88.7$ & $0.16 \pm 0.03$ & $35.0 \pm 0.2$ \\
LP-HAPC & $296.6 \pm 12.1$ & $0.15 \pm 0.01$ & $43.3 \pm 0.7$ \\
LP-DOTAP & $477.1 \pm 29.8$ & $0.21 \pm 0.01$ & $50.3 \pm 1.0$ \\
LP-DDAB & $573.2 \pm 25.8$ & $0.25 \pm 0.01$ & $56.2 \pm 1.5$ \\
LP-TC-1-12 & $467.8 \pm 15.6$ & $0.21 \pm 0.01$ & $47.9 \pm 1.7$ \\
\hline
\end{tabular}

$\mathrm{B}, 10 \mathrm{mM}$ sucrose

\begin{tabular}{lccc}
\hline Lipoplex $^{\mathrm{c}}$ & Size $^{\mathrm{b}}, \mathrm{nm}$ & PDI & $\zeta$-potential \\
& & $\mathrm{a}, \mathrm{mV}$ \\
\hline LP-OH & $553.8 \pm 60.8$ & $0.25 \pm 0.02$ & $37.5 \pm 1.0$ \\
LP-OH-C & $343.6 \pm 99.6$ & $0.19 \pm 0.03$ & $36.2 \pm 0.6$ \\
LP-HAPC & $264.9 \pm 9.9$ & $0.20 \pm 0.04$ & $37.8 \pm 1.0$ \\
LP-DOTAP & $435.9 \pm 6.1$ & $0.20 \pm 0.01$ & $38.9 \pm 0.9$ \\
LP-DDAB & $545.6 \pm 94.1$ & $0.26 \pm 0.02$ & $47.2 \pm 0.5$ \\
LP-TC-1-12 & $505.0 \pm 97.6$ & $0.23 \pm 0.04$ & $40.9 \pm 0.3$ \\
\hline
\end{tabular}

C, $50 \mathrm{mM}$ trehalose

\begin{tabular}{llcc}
\hline Lipoplex $^{\mathrm{c}}$ & Size $^{\mathrm{b}}, \mathrm{nm}$ & PDI & $\zeta$-potential \\
\hline LP-OH & $247.1 \pm 48.2$ & $0.17 \pm 0.06$ & $45.0 \pm 1.3$ \\
LP-OH-C & $248.5 \pm 28.6$ & $0.14 \pm 0.01$ & $45.5 \pm 0.7$ \\
L-HAPC & $184.3 \pm 6.2$ & $0.26 \pm 0.00$ & $40.6 \pm 0.7$ \\
LP-DOTAP & $295.4 \pm 30.1$ & $0.25 \pm 0.07$ & $49.4 \pm 0.7$ \\
LP-DDAB & $265.5 \pm 7.8$ & $0.26 \pm 0.01$ & $49.6 \pm 1.1$ \\
LP-TC-1-12 & $327.8 \pm 14.8$ & $0.16 \pm 0.00$ & $55.4 \pm 2.5$ \\
\hline
\end{tabular}

$\mathrm{D}, 50 \mathrm{mM}$ sucrose

\begin{tabular}{|c|c|c|c|}
\hline Lipoplex $^{\mathrm{c}}$ & Size $^{\mathrm{b}}, \mathrm{nm}$ & PDI & $\zeta$-potential ${ }^{\mathrm{a}}, \mathrm{mV}$ \\
\hline LP-OH & $297.9 \pm 37.7$ & $0.15 \pm 0.02$ & $37.4 \pm 1.1$ \\
\hline $\mathrm{P}-\mathrm{OH}-\mathrm{C}$ & $256.3 \pm 21.8$ & $0.12 \pm 0.01$ & $38.4 \pm 0.5$ \\
\hline LP-HAPC & $201.8 \pm 14.6$ & $0.17 \pm 0.06$ & $40.8 \pm 0.7$ \\
\hline LP-DOTAP & $207.0 \pm 3.6$ & $0.26 \pm 0.01$ & $46.2 \pm 1.2$ \\
\hline LP-DDAB & $308.8 \pm 18.0$ & $0.15 \pm 0.01$ & $45.6 \pm 1.0$ \\
\hline LP-TC-1-12 & $176.0 \pm 4.6$ & $0.22 \pm 0.02$ & $47.9 \pm 2.5$ \\
\hline
\end{tabular}

E, $100 \mathrm{mM}$ trehalose

\begin{tabular}{lccc}
\hline Lipoplex $^{\mathrm{c}}$ & Size $^{\mathrm{b}}, \mathrm{nm}$ & PDI & $\zeta$-potential \\
& & & \\
\hline LP-OH & $188.2 \pm 2.2$ & $0.25 \pm 0.05$ & $39.7 \pm 0.9$ \\
LP-OH-C & $168.8 \pm 5.2$ & $0.26 \pm 0.02$ & $41.1 \pm 1.7$ \\
LP-HAPC & $174.6 \pm 4.9$ & $0.23 \pm 0.01$ & $40.2 \pm 1.1$ \\
LP-DOTAP & $231.7 \pm 6.9$ & $0.24 \pm 0.01$ & $38.6 \pm 1.2$ \\
LP-DDAB & $240.5 \pm 9.9$ & $0.26 \pm 0.02$ & $44.5 \pm 1.4$ \\
LP-TC-1-12 & $186.9 \pm 6.4$ & $0.20 \pm 0.02$ & $42.6 \pm 0.4$
\end{tabular}

Table I. Continued.

F, $100 \mathrm{mM}$ sucrose

\begin{tabular}{lccc}
\hline Lipoplex $^{\mathrm{c}}$ & Size $^{\mathrm{b}}, \mathrm{nm}$ & PDI & $\zeta$-potential \\
& & $\mathrm{mV}$ \\
\hline LP-OH & $175.0 \pm 0.4$ & $0.26 \pm 0.01$ & $41.1 \pm 0.9$ \\
LP-OH-C & $190.0 \pm 5.7$ & $0.23 \pm 0.01$ & $39.6 \pm 0.6$ \\
LP-HAPC & $179.2 \pm 5.1$ & $0.26 \pm 0.02$ & $37.8 \pm 0.5$ \\
LP-DOTAP & $240.2 \pm 8.2$ & $0.25 \pm 0.01$ & $38.7 \pm 1.7$ \\
LP-DDAB & $230.6 \pm 2.7$ & $0.26 \pm 0.02$ & $49.5 \pm 0.2$ \\
LP-TC-1-12 & $177.5 \pm 6.8$ & $0.19 \pm 0.02$ & $49.0 \pm 1.3$ \\
\hline
\end{tabular}

${ }^{\mathrm{a}, \mathrm{b}}$ In water. ${ }^{\mathrm{c}}$ Charge ratio (+:-) of cationic lipid to siRNA phosphate (cationic liposomes composed of cationic cholesterol derivative, 7:1; cationic liposomes composed of dialkyl or trialkyl cationic lipid, 4:1). Data are presented as the mean $\pm \mathrm{SD}(\mathrm{n}=3)$. PDI, polydispersity index; LPs-OH, OH-Chol liposome; LP-OH-C, OH-C-Chol liposome; LP-HAPC, HAPC-Chol liposome; LP-DOTAP, DOTAP liposome; LP-DDAB, DDAB liposome; LP-TC-1-12, TC-1-12 liposome.

However, increasing concentrations of trehalose or sucrose present during vacuum-drying were associated with increased gene-silencing activity. LP-OH and LP-OH-C lipoplexes with Luc siRNA strongly suppressed luciferase activity when their lipoplexes were vacuum-dried at above $25 \mathrm{mM}$ trehalose or sucrose; however, LP-HAPC, LP-DOTAP, LP-DDAB, and LP-TC-1-12 lipoplexes with above $10 \mathrm{mM}$ trehalose or sucrose showed strong suppression of luciferase activity (Figs. 3 and 4). These results indicated that higher concentration of disaccharide in vacuum-drying might be needed for LP-OH and LP-OH-C lipoplexes to keep gene silencing activity compared with other formulations. The largest difference in gene-silencing activities of between vacuum-dried siRNA lipoplexes (Figs. 3 and 4) and freeze-dried siRNA lipoplexes (12) with trehalose or sucrose was not observed in any of the cationic liposomes tested. From these findings, in Rev-transfection, the freezing process before vacuum-drying of siRNA lipoplexes did not affect the gene-silencing activity of siRNA lipoplexes.

Characterization of freeze-dried siRNA lipoplexes after reconstitution. A variety of saccharides including glucose, fructose, maltose, and lactose have also been shown to act as cryoprotectants during dehydration/rehydration of liposomes and nanoparticles $(18,20)$. Yadava et al reported that DOTAP/DOPE lipoplexes freeze-dried in the presence of $278 \mathrm{mM}$ glucose and lactose exhibited gene-silencing effects without loss of transfection activity when they were rehydrated with water and then transfected into cells (conventional transfection) (6). However, to the best of our knowledge, in Rev-transfection with freeze-dried siRNA lipoplexes, there are still few reports on the application of saccharides except trehalose and sucrose as cryoprotectants. Therefore, we prepared cakes of mono-, di-, and trisaccharides by freeze-drying, and compared their appearance among saccharide types. Here, we used four monosaccharides (glucose, fructose, galactose, or mannose), six disaccharides (sucrose, trehalose, maltose, 


\begin{tabular}{rlrc}
\multicolumn{4}{c}{ Saccharide solution $(125 \mu \mathrm{l} /$ well $)$} \\
\hline & Mono- & Di- & Tri- \\
$10 \mathrm{mM}$ & $0.23 \mathrm{mg}$ & $0.43 \mathrm{mg}$ & $0.63 \mathrm{mg}$ \\
$25 \mathrm{mM}$ & $0.56 \mathrm{mg}$ & $1.1 \mathrm{mg}$ & $1.6 \mathrm{mg}$ \\
$50 \mathrm{mM}$ & $1.1 \mathrm{mg}$ & $2.1 \mathrm{mg}$ & $3.2 \mathrm{mg}$ \\
$100 \mathrm{mM}$ & $2.3 \mathrm{mg}$ & $4.3 \mathrm{mg}$ & $6.3 \mathrm{mg}$ \\
$150 \mathrm{mM}$ & $3.4 \mathrm{mg}$ & $6.4 \mathrm{mg}$ & $9.5 \mathrm{mg}$ \\
$280 \mathrm{mM}$ & $6.3 \mathrm{mg}$ & $12.0 \mathrm{mg}$ & $18 \mathrm{mg}$
\end{tabular}

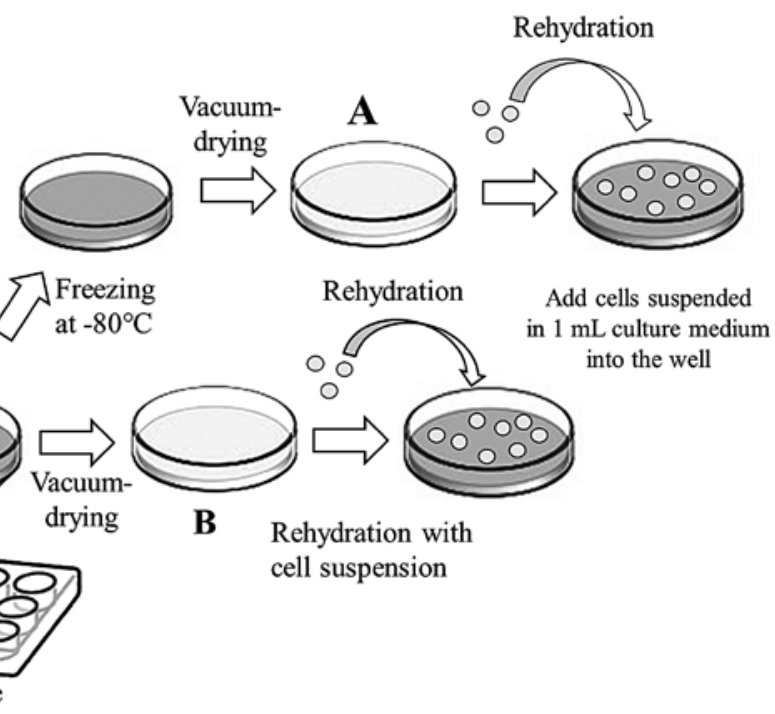

A: Freeze-dried well

B: Vacuum-dried well without pre-freezing

Figure 2. Schematic diagram of reverse transfection with freeze-dried siRNA lipoplexes and vacuum-dried siRNA lipoplexes. siRNA lipoplexes were diluted in saccharide solution and then transferred to 12-well plates, followed by (A) freeze-drying or (B) vacuum-drying. Freeze-dried or vacuum-dried siRNA lipoplexes in the plate were reconstituted by the addition of cells suspended in culture medium $(1 \mathrm{ml})$. siRNA, small interfering RNA.
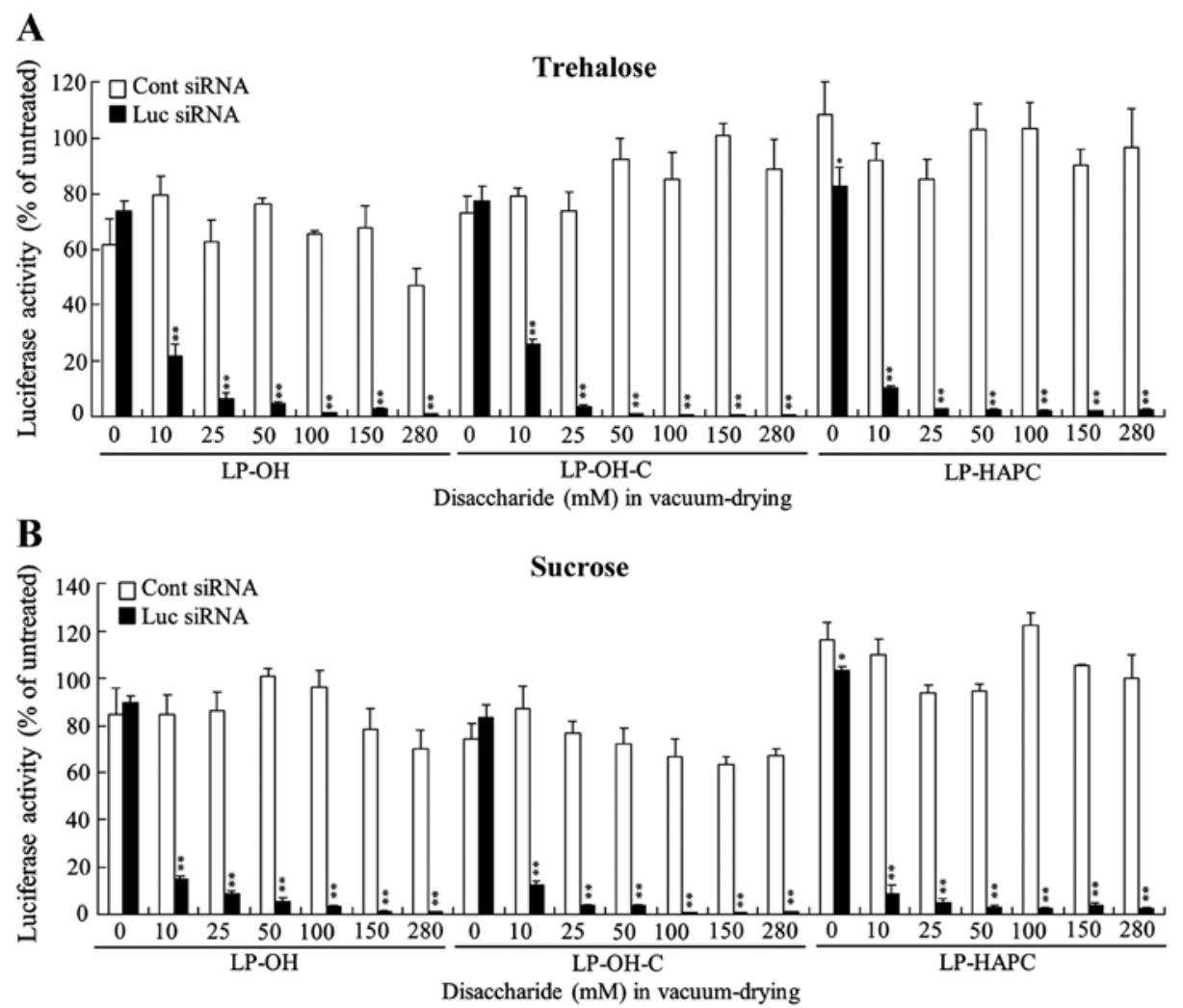

Figure 3. Effect of trehalose and sucrose during vacuum-drying of siRNA lipoplexes on the suppression of luciferase expression in MCF-7-Luc cells after reverse transfection with siRNA lipoplexes. LP-OH, LP-OH-C and LP-HAPC lipoplexes with 50 pmol Luc siRNA or Cont siRNA were diluted in $125 \mu 1$ of $10,25,50,100,150$ or $280 \mathrm{mM}(0.43,1.1,2.1,4.3,6.4$ and $12.0 \mathrm{mg}$, respectively) (A) trehalose or (B) sucrose and then transferred to 12-well plates, followed by vacuum-drying. Data are presented as the mean $\pm \mathrm{SD}(\mathrm{n}=3)$. ${ }^{*} \mathrm{P}<0.05$ and ${ }^{* *} \mathrm{P}<0.01$ vs. Cont siRNA. siRNA, small interfering RNA; Luc, luciferase; Cont, control; LP-OH, OH-Chol liposome; LP-OH-C, OH-C-Chol liposome; LP-HAPC, HAPC-Chol liposome.

lactose, lactulose, or cellobiose), and two trisaccharides (raffinose or melezitose) for the preparation of freeze-dried saccharides. As a result, large cakes were observed after freeze-drying of 25 or $100 \mathrm{mM}$ di- and trisaccharide solutions; however, insufficient cakes were observed in freeze-drying of monosaccharide solutions (Fig. 5). 
A

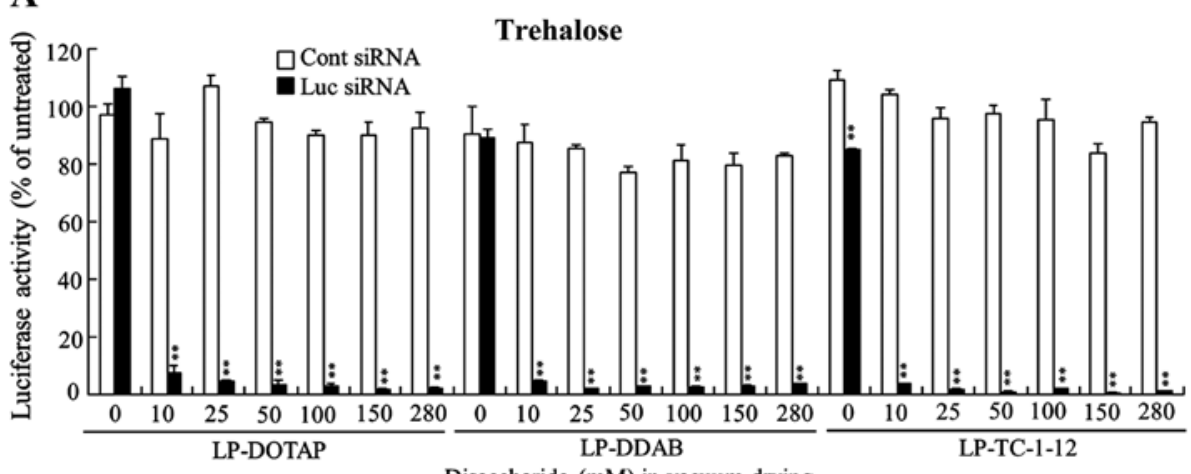

Disaccharide $(\mathrm{mM})$ in vacuum-drying

B

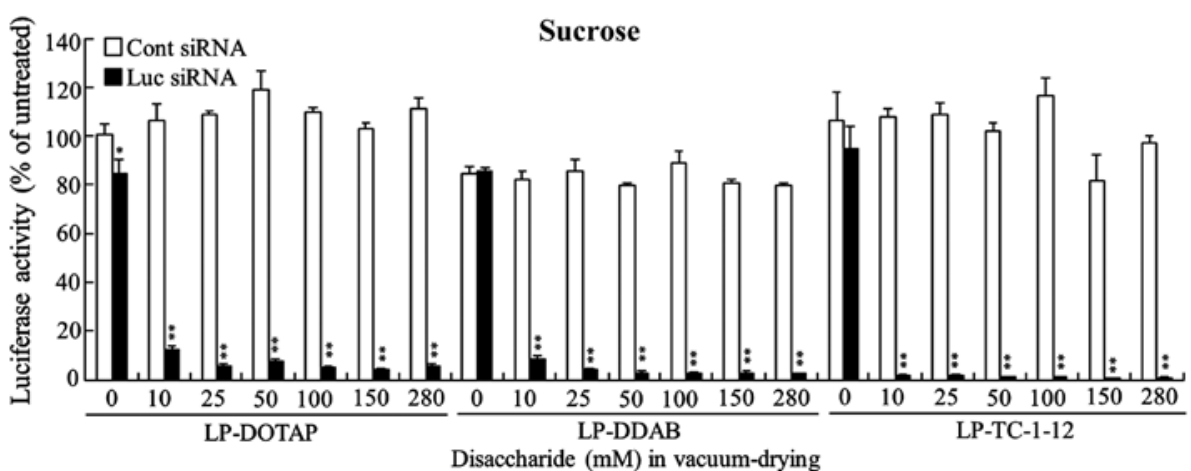

Figure 4. Effect of trehalose and sucrose during vacuum-drying of siRNA lipoplexes on the suppression of luciferase expression in MCF-7-Luc cells after reverse transfection with siRNA lipoplexes. LP-DOTAP, LP-DDAB and LP-TC-1-12 lipoplexes with 50 pmol Luc siRNA or Cont siRNA were diluted in $125 \mu 1$ of 10,25, 50,100, 150, or $280 \mathrm{mM}(0.43,1.1,2.1,4.3,6.4$ and $12.0 \mathrm{mg}$, respectively) (A) trehalose or (B) sucrose and then transferred to 12-well plates, followed by vacuum-drying. Data are presented as the mean $\pm \mathrm{SD}(\mathrm{n}=3) .{ }^{*} \mathrm{P}<0.05$ and ${ }^{* *} \mathrm{P}<0.01$ vs. Cont siRNA. siRNA, small interfering RNA; Luc, luciferase; Cont, control; LP-DOTAP, DOTAP liposome; LP-DDAB, DDAB liposome; LP-TC-1-12, TC-1-12 liposome.
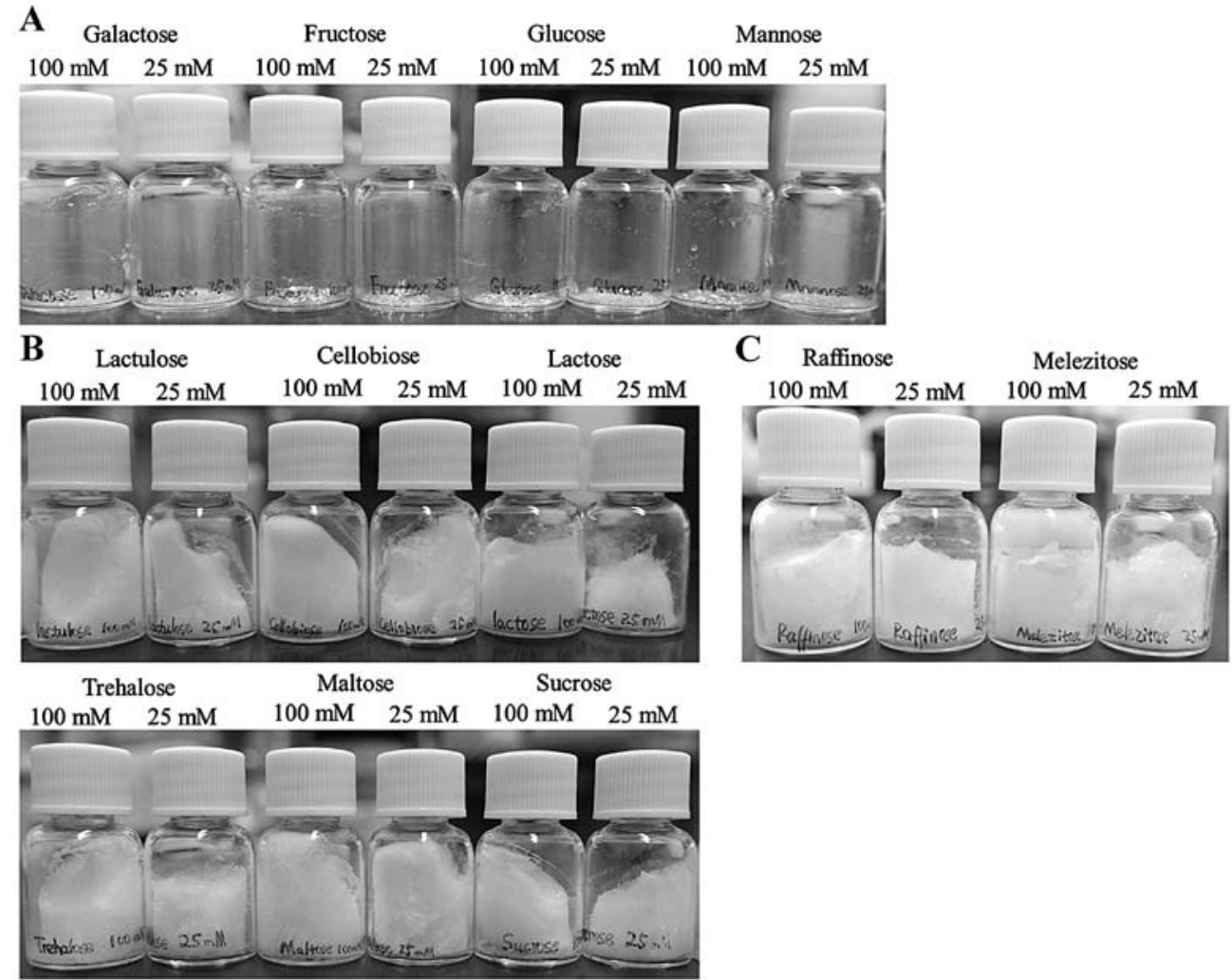

Figure 5. Appearance of cakes after freeze-drying saccharide solution. (A) A total 25 or $100 \mathrm{mM}$ monosaccharide solution (glucose, fructose, galactose or mannose), (B) disaccharide solution (sucrose, trehalose, maltose, lactose, lactulose or cellobiose) or (C) trisaccharide solution (raffinose or melezitose) were transferred into $5 \mathrm{ml}$ vials, followed by freezing at $-80^{\circ} \mathrm{C}$. The frozen vials were dried in a high vacuum using a freeze-dryer. 
Table II. Particle size and $\zeta$-potential of siRNA lipoplexes after the rehydration of freeze-dried lipoplexes.

A, LP-DOTAP lipoplexes ${ }^{\mathrm{a}}$

\begin{tabular}{llcc}
\hline $\begin{array}{l}\text { Saccharide, } \\
25 \mathrm{mM}\end{array}$ & Size $^{\mathrm{b}}, \mathrm{nm}$ & PDI & $\begin{array}{c}\zeta \text {-potential } \\
\mathrm{mV}\end{array}$ \\
\hline Glucose & $322.3 \pm 5.5$ & $0.27 \pm 0.01$ & $45.1 \pm 2.2$ \\
Fructose & $321.3 \pm 13.9$ & $0.28 \pm 0.02$ & $47.6 \pm 1.0$ \\
Galactose & $231.6 \pm 7.3$ & $0.29 \pm 0.01$ & $40.4 \pm 0.7$ \\
Mannose & $312.0 \pm 44.3$ & $0.22 \pm 0.05$ & $43.0 \pm 0.7$ \\
Maltose & $185.0 \pm 3.9$ & $0.25 \pm 0.01$ & $50.1 \pm 0.3$ \\
Lactose & $182.4 \pm 6.5$ & $0.26 \pm 0.01$ & $37.2 \pm 0.7$ \\
Lactulose & $195.4 \pm 2.5$ & $0.26 \pm 0.02$ & $41.0 \pm 0.8$ \\
Cellobiose & $184.1 \pm 1.6$ & $0.25 \pm 0.01$ & $44.6 \pm 1.1$ \\
Raffinose & $183.2 \pm 2.7$ & $0.25 \pm 0.01$ & $36.3 \pm 0.4$ \\
Melezitose & $206.0 \pm 11.1$ & $0.26 \pm 0.01$ & $27.5 \pm 1.3$ \\
\hline
\end{tabular}

B, LP-DDAB lipoplexes ${ }^{\mathrm{a}}$

\begin{tabular}{lccc}
\hline $\begin{array}{l}\text { Saccharide, } \\
25 \mathrm{mM}\end{array}$ & Size $^{\mathrm{b}}, \mathrm{nm}$ & PDI & $\begin{array}{c}\zeta \text {-potential } \\
\mathrm{mV}\end{array}$ \\
\hline Glucose & $459.3 \pm 56.2$ & $0.21 \pm 0.02$ & $46.6 \pm 0.9$ \\
Fructose & $1,041.8 \pm 266.1$ & $0.42 \pm 0.09$ & $45.7 \pm 1.4$ \\
Galactose & $648.0 \pm 21.9$ & $0.29 \pm 0.01$ & $47.6 \pm 1.6$ \\
Mannose & $323.9 \pm 27.7$ & $0.15 \pm 0.01$ & $53.9 \pm 2.7$ \\
Maltose & $215.9 \pm 23.4$ & $0.19 \pm 0.06$ & $45.2 \pm 1.3$ \\
Lactose & $162.3 \pm 3.0$ & $0.18 \pm 0.00$ & $36.7 \pm 2.8$ \\
Lactulose & $217.0 \pm 13.8$ & $0.23 \pm 0.01$ & $38.8 \pm 0.4$ \\
Cellobiose & $173.3 \pm 3.8$ & $0.22 \pm 0.02$ & $44.6 \pm 1.2$ \\
Raffinose & $174.7 \pm 1.3$ & $0.22 \pm 0.03$ & $46.9 \pm 2.2$ \\
Melezitose & $247.8 \pm 34.4$ & $0.20 \pm 0.06$ & $36.4 \pm 1.6$ \\
\hline
\end{tabular}

C, LP-DOTAP lipoplexes ${ }^{\mathrm{a}}$

\begin{tabular}{lccc}
\hline $\begin{array}{l}\text { Saccharide, } \\
100 \mathrm{mM}\end{array}$ & $\begin{array}{c}\text { Size }^{\mathrm{b}}, \\
\mathrm{nm}\end{array}$ & PDI & $\begin{array}{c}\zeta \text {-potential } \\
\mathrm{mV}\end{array}$ \\
\hline Glucose & $173.5 \pm 3.6$ & $0.24 \pm 0.01$ & $47.8 \pm 3.5$ \\
Fructose & $219.6 \pm 0.6$ & $0.24 \pm 0.02$ & $46.5 \pm 0.7$ \\
Galactose & $187.6 \pm 4.9$ & $0.24 \pm 0.01$ & $50.5 \pm 1.1$ \\
Mannose & $219.6 \pm 0.6$ & $0.24 \pm 0.02$ & $46.5 \pm 0.7$ \\
Maltose & $182.2 \pm 7.7$ & $0.19 \pm 0.01$ & $30.6 \pm 0.6$ \\
Lactose & $187.3 \pm 1.3$ & $0.14 \pm 0.01$ & $30.9 \pm 0.6$ \\
Lactulose & $188.8 \pm 6.4$ & $0.14 \pm 0.01$ & $46.3 \pm 0.7$ \\
Cellobiose & $169.9 \pm 1.9$ & $0.21 \pm 0.02$ & $42.8 \pm 0.7$ \\
Raffinose & $207.7 \pm 8.5$ & $0.24 \pm 0.00$ & $40.8 \pm 0.8$ \\
Melezitose & $185.0 \pm 4.7$ & $0.18 \pm 0.01$ & $37.2 \pm 0.9$ \\
\hline
\end{tabular}

D, LP-DDAB lipoplexes ${ }^{\mathrm{a}}$

\begin{tabular}{lccc}
\hline $\begin{array}{l}\text { Saccharide, } \\
100 \mathrm{mM}\end{array}$ & $\begin{array}{c}\text { Size }^{\mathrm{b}}, \\
\mathrm{nm}\end{array}$ & PDI & $\begin{array}{c}\zeta \text {-potential } \\
\mathrm{mV}\end{array}$ \\
\hline Glucose & $171.9 \pm 4.1$ & $0.23 \pm 0.01$ & $43.8 \pm 1.9$
\end{tabular}

Table II. Continued.

D, LP-DDAB lipoplexes ${ }^{\mathrm{a}}$

\begin{tabular}{llcc}
\hline $\begin{array}{l}\text { Saccharide, } \\
100 \mathrm{mM}\end{array}$ & Size $^{\mathrm{b}}, \mathrm{nm}$ & PDI & $\begin{array}{c}\text { S-potential } \\
\mathrm{mV}\end{array}$ \\
\hline Fructose & $232.2 \pm 30.4$ & $0.22 \pm 0.09$ & $40.9 \pm 1.6$ \\
Galactose & $235.6 \pm 38.3$ & $0.20 \pm 0.05$ & $43.3 \pm 2.3$ \\
Mannose & $193.0 \pm 8.6$ & $0.25 \pm 0.04$ & $36.1 \pm 1.6$ \\
Maltose & $193.1 \pm 0.8$ & $0.22 \pm 0.00$ & $43.5 \pm 2.2$ \\
Lactose & $188.9 \pm 2.7$ & $0.20 \pm 0.01$ & $35.8 \pm 0.3$ \\
Lactulose & $196.7 \pm 8.5$ & $0.23 \pm 0.04$ & $44.8 \pm 1.3$ \\
Cellobiose & $179.8 \pm 3.2$ & $0.24 \pm 0.00$ & $40.1 \pm 0.4$ \\
Raffinose & $162.5 \pm 0.8$ & $0.18 \pm 0.01$ & $44.1 \pm 1.5$ \\
Melezitose & $197.7 \pm 1.7$ & $0.21 \pm 0.01$ & $15.3 \pm 1.0$ \\
\hline
\end{tabular}

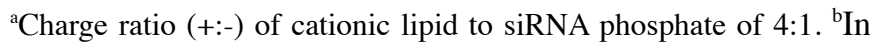
water. Data are presented as the mean \pm SD $(n=3)$. PDI, polydispersity index; siRNA, small interfering RNA.

Next, to examine whether the saccharide types during freeze-drying affected the size of siRNA lipoplexes after rehydration, we prepared freeze-dried siRNA lipoplexes in the presence of 25 or $100 \mathrm{mM}$ mono-, di-, or trisaccharide solutions, and measured the sizes of the siRNA lipoplexes after rehydration (Table II). In subsequent experiments, we decided to use LP-DDAB and LP-DOTAP for preparation of freeze-dried siRNA lipoplexes. In addition, we used ten kind of saccharides except the trehalose and sucrose for preparation of freeze-dried siRNA lipoplexes, because we have already reported that both trehalose and sucrose have been useful as a cryoprotectant for Rev-transfection with freeze-dried siRNA lipoplexes (12).

In freeze-drying in $25 \mathrm{mM}$ monosaccharide solution, LP-DOTAP, and LP-DDAB lipoplexes exhibited larger in size $(\sim 230-1000 \mathrm{~nm})$ than those $(160-250 \mathrm{~nm})$ in $25 \mathrm{mM}$ di- and trisaccharide solutions. However, siRNA lipoplexes were approximately $160-240 \mathrm{~nm}$ in size (0.14-0.25 in PDI) when they were freeze-dried in $100 \mathrm{mM}$ saccharide solution regardless of the saccharide type. These results indicated that the presence of $100 \mathrm{mM}$ saccharide during freeze-drying did not greatly increase the size of siRNA lipoplexes.

Effect of saccharide types in freeze-drying of siRNA lipoplexes on gene-silencing effects in the cells by Rev-transfection. To examine whether the saccharide types during freeze-drying affected the gene-silencing effects by Rev-transfection with siRNA lipoplexes, freeze-dried siRNA lipoplexes were reconstituted with $\mathrm{MCF}-7-\mathrm{Luc}$ cells suspended in culture medium. LP-DDAB, and LP-DOTAP lipoplexes with Luc siRNA did not suppress luciferase activity when their lipoplexes were freeze-dried without mono-, di-, or trisaccharides (Figs. 6-8). However, increasing concentrations of saccharides present during freeze-drying were associated with increased gene-silencing activity regardless of the saccharide types, and those with above $25 \mathrm{mM}$ saccharide showed strong suppression of luciferase activity ( $>80 \%$ knockdown, compared with 

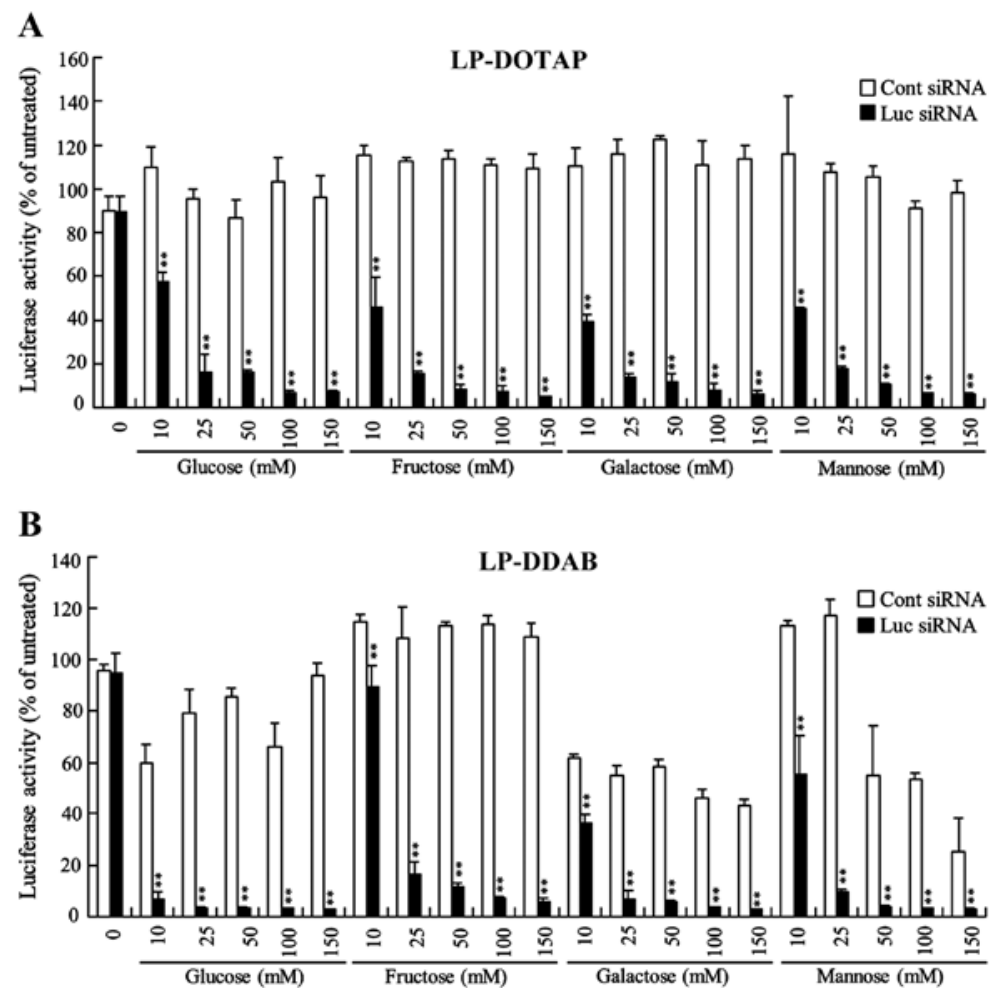

Figure 6. Effect of monosaccharides during the freeze-drying of siRNA lipoplexes on the suppression of luciferase expression in MCF-7-Luc cells after reverse transfection. (A) LP-DOTAP and (B) LP-DDAB lipoplexes with 50 pmol Luc siRNA or Cont siRNA were diluted in 125 $\mu 1$ of 10, 25, 50, 100, or 150 mM glucose, fructose, galactose or mannose solution and then transferred to 12-well plates, followed by freeze-drying. MCF-7-Luc cells suspended in culture medium $(1 \mathrm{ml})$ were added to the well and luciferase assays were performed after incubation for $48 \mathrm{~h}$ at $37^{\circ} \mathrm{C}$. Data are presented as the mean $\pm \mathrm{SD}(\mathrm{n}=3)$. ${ }^{* *} \mathrm{P}<0.01$ vs. Cont siRNA. siRNA, small interfering RNA; Luc, luciferase; Cont, control; LP-DOTAP, DOTAP liposome; LP-DDAB, DDAB liposome.
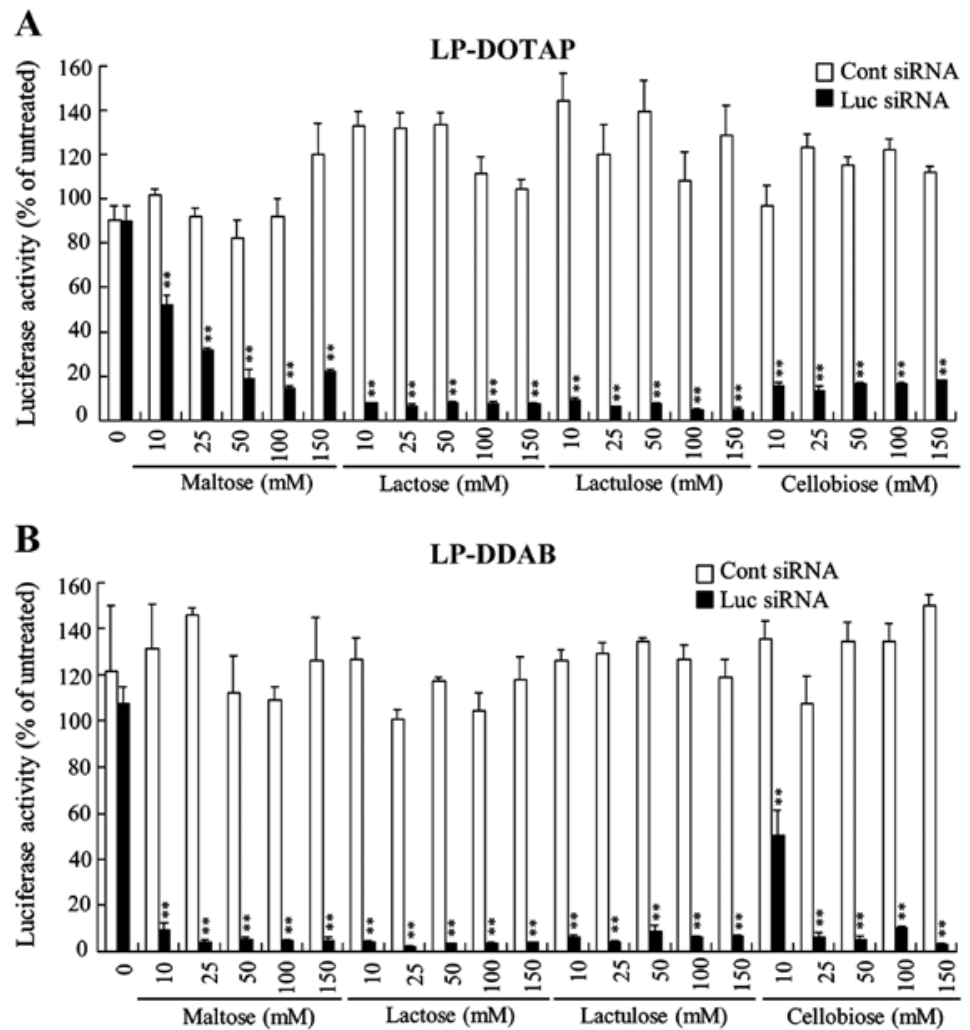

Figure 7. Effect of disaccharide during the freeze-drying of siRNA lipoplexes on the suppression of luciferase expression in MCF-7-Luc cells after reverse transfection. (A) LP-DOTAP and (B) LP-DDAB lipoplexes with 50 pmol Luc siRNA or Cont siRNA were diluted in 125 $\mu 1$ of 10, 25, 50, 100, or 150 mM maltose, lactose, lactulose or cellobiose solution and then transferred to 12-well plates, followed by freeze-drying. MCF-7-Luc cells suspended in culture medium $(1 \mathrm{ml})$ were added to the well, and luciferase assays were performed after incubation for $48 \mathrm{~h}$ at $37^{\circ} \mathrm{C}$. Data are presented as the mean $\pm \mathrm{SD}(\mathrm{n}=3)$. ${ }^{* *} \mathrm{P}<0.01$ vs. Cont siRNA. siRNA, small interfering RNA; Luc, luciferase; Cont, control; LP-DOTAP, DOTAP liposome; LP-DDAB, DDAB liposome. 
A

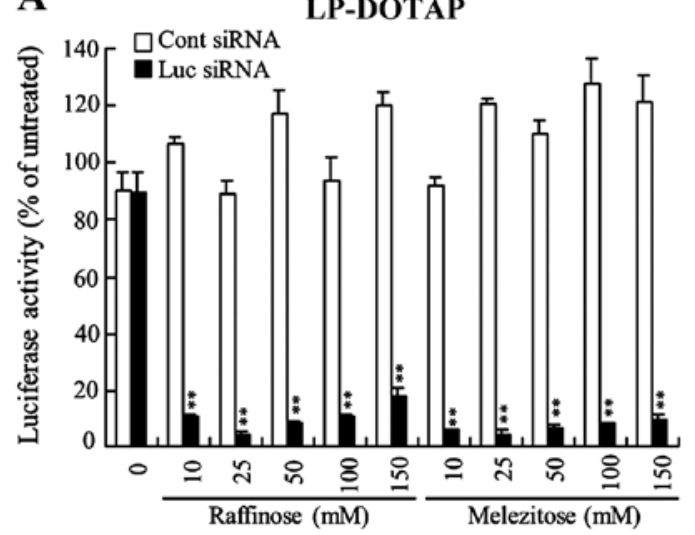

B

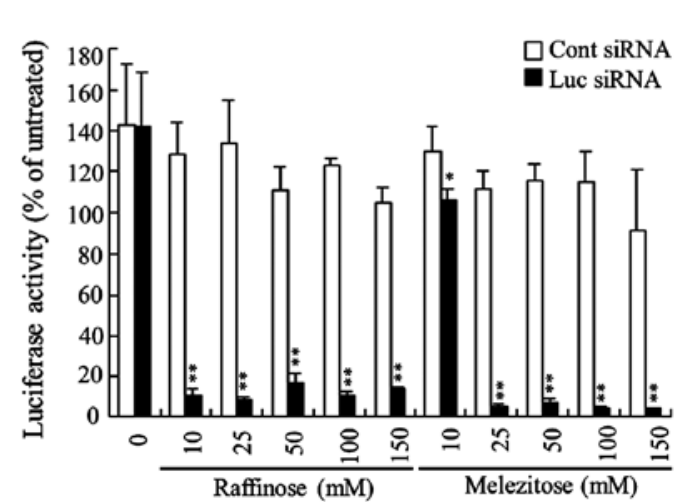

Figure 8. Effect of trisaccharide during the freeze-drying of siRNA lipoplexes on the suppression of luciferase expression in MCF-7-Luc cells after reverse transfection. (A) LP-DOTAP and (B) LP-DDAB lipoplexes with 50 pmol Luc siRNA or Cont siRNA were diluted in 125 $\mu 1$ of 10, 25, 50, 100, or 150 mM raffinose or melezitose solution and then transferred to 12-well plates, followed by freeze-drying. MCF-7-Luc cells suspended in culture medium (1 ml) were added to the well, and luciferase assays were performed after incubation for $48 \mathrm{~h}$ at $37^{\circ} \mathrm{C}$. Data are presented as the mean $\pm \mathrm{SD}(\mathrm{n}=3)$. ${ }^{*} \mathrm{P}<0.05$ and ${ }^{* * *} \mathrm{P}<0.01 \mathrm{vs}$. Cont siRNA. siRNA, small interfering RNA; Luc, luciferase; Cont, control; LP-DOTAP, DOTAP liposome; LP-DDAB, DDAB liposome.

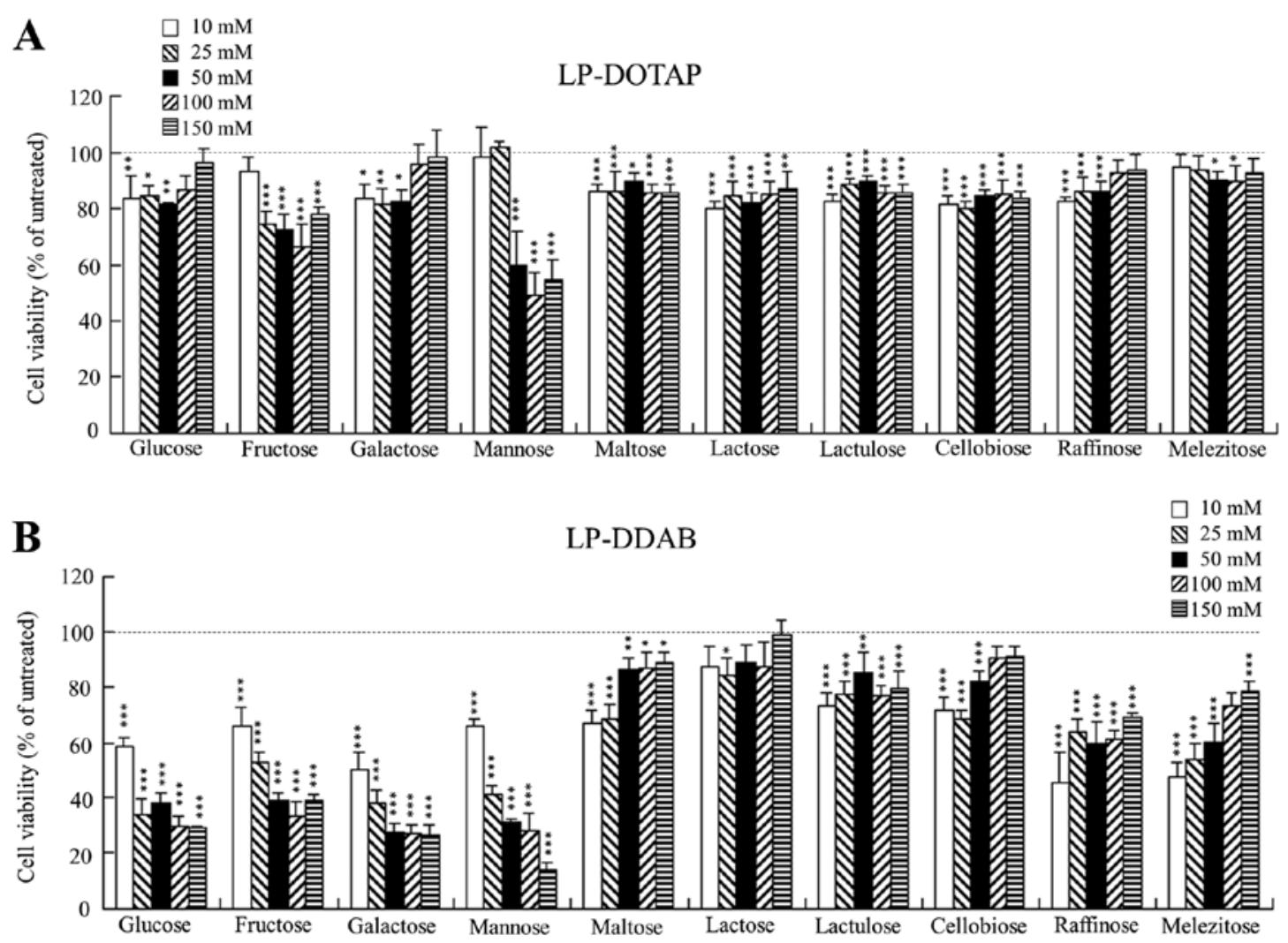

Figure 9. MCF-7-Luc cell viability $24 \mathrm{~h}$ after reverse transfection with freeze-dried siRNA lipoplexes. (A) LP-DOTAP and (B) LP-DDAB lipoplexes of 5 pmol Cont siRNA were diluted in $12.5 \mu \mathrm{l}$ of $10,25,50,100$, or $150 \mathrm{mM}$ mono-, di- or trisaccharide solution and then transferred to 96-well plates, followed by freeze-drying. MCF-7-Luc cells suspended in culture medium $(100 \mu \mathrm{l})$ were added to the plate (final, $50 \mathrm{nM}$ siRNA). After a 24 -h incubation period at $37^{\circ} \mathrm{C}$, cell viabilities were measured using Cell Counting Kit-8, and were expressed as relative to that of untransfected cells. Data are presented as the mean \pm SD $(\mathrm{n}=3)$. Luc, luciferase; siRNA, small interfering RNA; Cont, control. ${ }^{*} \mathrm{P}<0.05,{ }^{* * *} \mathrm{P}<0.01$ and ${ }^{* * * *} \mathrm{P}<0.001$ vs. untransfected cells. LP-DOTAP, DOTAP liposome; LP-DDAB, DDAB liposome.

untreated cells) (Figs. 6-8). However, in Rev-transfection with LP-DDAB lipoplexes of Cont siRNA, freeze-drying in glucose, galactose, or mannose induced non-specific gene-silencing (Fig. 6B), indicating that the off-targeted effect induced by Rev-transfection with siRNA lipoplexes may be dependent on the combination of cationic liposomes and saccharide.
Cytotoxicity by Rev-transfections with freeze-dried siRNA lipoplexes. To examine cytotoxicity by Rev-transfection with freeze-dried siRNA lipoplexes, we measured cell viabilities at $24 \mathrm{~h}$ after Rev-transfections with siRNA lipoplexes into MCF-7 cells. For all the siRNA lipoplexes tested, Rev-transfection did not show high cytotoxicity when 
the siRNA lipoplexes were freeze-dried with disaccharides (Fig. 9A and B); however, with an increase in the concentration of monosaccharide in freeze-drying, the cytotoxicity after Rev-transfection was increased (Fig. 9A and B). In addition, the presence of trisaccharide in freeze-drying of LP-DDAB lipoplexes also exhibited moderate cytotoxicity after Rev-transfection (Fig. 9). We speculated that insufficient cakes after freeze-drying of monosaccharide solutions (Fig. 5) might affect cell viability by Rev-transfection. However, the mechanism why the presence of monosaccharide or trisaccharide during freeze-drying induced cytotoxicity for the cells was not clear. We reported previously that LP-DOTAP and LP-DDAB lipoplexes freeze-dried in $100 \mathrm{mM}$ trehalose or sucrose exhibited minimal toxicity $(\sim 70-80 \%$ cell viability) (12). These findings suggested that disaccharides may be suitable as a cyroprotectant during the freeze-drying of siRNA lipoplexes for Rev-transfection.

In Rev-transfection with polyethylenimine (PEI)/plasmid DNA (pDNA) complexes (polyplexes), the presence of low concentrations of sucrose $[<1 \%(29.2 \mathrm{mM})]$ duringfreeze-drying did not have a notable influence to pDNA transfection efficacy whereas higher concentration $[>5 \%(146 \mathrm{mM})]$ reduced the transfection efficiency (21). In contrast, in our study, regardless of the saccharide types used in the preparation of freeze-dried siRNA lipoplexes, the presence of 25-150 mM saccharides during the freeze-drying of siRNA lipoplexes exhibited efficient gene-silencing, indicating that Rev-transfection using cationic liposomes might not be notably affected by concentration of saccharide, compared with that using cationic polymer. However, DDAB lipoplexes freeze-dried with monoand trisaccharides induced off-targeted effects (Fig. 6B) or moderate toxicity (Fig. 9B) although they exhibited efficient gene-silencing effects. Therefore, for Rev-transfection with freeze-dried siRNA lipoplexes, it will be necessary to find optimal saccharides that can induce efficient gene-silencing without off-target effects and cytotoxicity. Here, we found that the presence of maltose, lactose, lactulose, and cellobiose during the freeze-drying of siRNA lipoplexes could induce gene-silencing activity without cytotoxicity by Rev-transfection as well as sucrose and trehalose. This study provides valuable information about the Rev-transfection with freeze-dried or vacuum-dried siRNA lipoplexes for efficient siRNA delivery into the cells.

In this study, we evaluated the effects of freezing before vacuum-drying of siRNA lipoplexes on gene-silencing by Rev-transfection, and found that freezing process did not affect the gene-silencing activity by siRNA lipoplexes. In addition, regardless of the type of mono-, di-, and trisaccharides in freeze-drying of siRNA lipoplexes, Rev-transfection can induce efficient gene-silencing; however, disaccharides exhibited higher cell viability after Rev-transfection compared with mono- and trisaccharides. These findings suggested that use of disaccharides will be suitable for the preparation of freeze-dried or vacuum-dried siRNA lipoplexes in Rev-transfection.

\section{Acknowledgements}

The authors would like to thank Mr. Reo Yamagishi and Mr. Shun Fujishita (Department of Molecular Pharmaceutics,
Hoshi University) for assistance with the experimental work assessing the in vitro gene-silencing effect.

\section{Funding}

No funding was received.

\section{Availability of data and materials}

The datasets used and/or analyzed during the current study are available from the corresponding author on reasonable request.

\section{Authors' contributions}

YH conceived and designed the study. Experiments were performed by MT and SH. YH wrote the manuscript. All authors have read and approved the final manuscript.

\section{Ethics approval and consent to participate}

Not applicable.

\section{Patient consent for publication}

Not applicable.

\section{Competing interests}

The authors declare that they have no competing interests.

\section{References}

1. Wilson RC and Doudna JA: Molecular mechanisms of RNA interference. Annu Rev Biophys 42: 217-239, 2013.

2. Erfle H, Neumann B, Liebel U, Rogers P, Held M, Walter T, Ellenberg $\mathrm{J}$ and Pepperkok R: Reverse transfection on cell arrays for high content screening microscopy. Nat Protoc 2: 392-399, 2007.

3. Zhang S, Zhi D and Huang L: Lipid-based vectors for siRNA delivery. J Drug Target 20: 724-735, 2012.

4. Chen C, Han D, Cai C and Tang X: An overview of liposome lyophilization and its future potential. J Control Release 142: 299-311, 2010.

5. Franzé S, Selmin F, Samaritani E, Minghetti P and Cilurzo F: Lyophilization of liposomal formulations: Still necessary, still challenging. Pharmaceutics 10: 139, 2018.

6. Yadava P, Gibbs M, Castro C and Hughes JA: Effect of lyophilization and freeze-thawing on the stability of siRNA-liposome complexes. AAPS PharmSciTech 9: 335-341, 2008.

7. Andersen MØ, Howard KA, Paludan SR, Besenbacher F and Kjems J: Delivery of siRNA from lyophilized polymeric surfaces. Biomaterials 29: 506-512, 2008.

8. Kundu AK, Chandra PK, Hazari S, Ledet G, Pramar YV, Dash S and Mandal TK: Stability of lyophilized siRNA nanosome formulations. Int J Pharm 423: 525-534, 2012.

9. Ball RL, Bajaj P and Whitehead KA: Achieving long-term stability of lipid nanoparticles: Examining the effect of $\mathrm{pH}$, temperature, and lyophilization. Int J Nanomedicine 12: 305-315, 2016.

10. Fujita S, Ota E, Sasaki C, Takano K, Miyake M and Miyake J: Highly efficient reverse transfection with siRNA in multiple wells of microtiter plates. J Biosci Bioeng 104: 329-333, 2007.

11. Wu K, Xu J, Liu M, Song W, Yan J, Gao S, Zhao L and Zhang Y: Induction of osteogenic differentiation of stem cells via a lyophilized microRNA reverse transfection formulation on a tissue culture plate. Int J Nanomedicine 8: 1595-1607, 2013.

12. Hattori Y, Hu S and Onishi H: Effects of cationic lipids in cationic liposomes and disaccharides in the freeze-drying of siRNA lipoplexes on gene silencing in cells by reverse transfection. J Liposome Res (In press). 
13. Ding $W$, Hattori $Y$, Higashiyama $K$ and Maitani $Y$ : Hydroxyethylated cationic cholesterol derivatives in liposome vectors promote gene expression in the lung. Int J Pharm 354: 196-203, 2008

14. Hattori Y, Hara E, Shingu Y, Minamiguchi D, Nakamura A, Arai S, Ohno H, Kawano K, Fujii N and Yonemochi E: siRNA delivery into tumor cells by cationic cholesterol derivative-based nanoparticles and liposomes. Biol Pharm Bull 38: 30-38, 2015.

15. Hattori Y, Nakamura T, Ohno H, Fujii N and Maitani Y: siRNA delivery into tumor cells by lipid-based nanoparticles composed of hydroxyethylated cholesteryl triamine. Int J Pharm 443: 221-229, 2013.

16. Hattori Y, Nakamura M, Takeuchi N, Tamaki K, Shimizu S, Yoshiike Y, Taguchi M, Ohno H, Ozaki KI and Onishi H: Effect of cationic lipid in cationic liposomes on siRNA delivery into the lung by intravenous injection of cationic lipoplex. J Drug Target 27: 217-227, 2019.

17. Hattori Y, Nakamura A, Arai S, Kawano K, Maitani Y and Yonemochi E: siRNA delivery to lung-metastasized tumor by systemic injection with cationic liposomes. J Liposome Res 25 : 279-286, 2015
18. Abdelwahed W, Degobert G, Stainmesse S and Fessi H: Freeze-drying of nanoparticles: Formulation, process and storage considerations. Adv Drug Deliv Rev 58: 1688-1713, 2006.

19. Hattori Y, Nakamura M, Takeuchi N, Tamaki K, Ozaki KI and Onishi H: Effect of cationic lipid type in PEGylated liposomes on siRNA delivery following the intravenous injection of siRNA lipoplexes. World Acad Sci J 1: 74-85, 2019.

20. Crowe LM, Crowe JH, Rudolph A, Womersley C and Appel L: Preservation of freeze-dried liposomes by trehalose. Arch Biochem Biophys 242: 240- 247, 1985.

21. Reinisalo M, Urtti A and Honkakoski P: Freeze-drying of cationic polymer DNA complexes enables their long-term storage and reverse transfection of post-mitotic cells. J Control Release 110: 437-443, 2006.

(i) $\Theta$ This work is licensed under a Creative Commons International (CC BY-NC-ND 4.0) License. 